\title{
Misuse of prescription and illicit drugs among high-risk young adults in Los Angeles and New York
}

\author{
Stephen E. Lankenau, ${ }^{1}$ Sheree M. Schrager, ${ }^{2}$ Karol Silva, ${ }^{1}$ Alex Kecojevic, ${ }^{1}$ \\ Jennifer Jackson Bloom, ${ }^{3}$ Carolyn Wong, ${ }^{3}$ Ellen Iverson ${ }^{2}$ \\ ${ }^{1}$ Drexel University, School of Public Health, Department of Community Health and Prevention, \\ Philadelphia, PA; ${ }^{2}$ Children's Hospital Los Angeles, Division of Adolescent Medicine, Los Angeles, \\ CA; ${ }^{3}$ Children's Hospital Los Angeles, Division of Research on Children, Youth and Families, \\ Los Angeles, CA, USA
}

Significance for public health

Prescription drug misuse among young adults is increasingly viewed as a public health concern in the US, since it is associated with various risk practices. Research examining prescription drug misuse among high-risk groups of young adults is limited. Large metropolitan areas, such as Los Angeles (LA) and New York (NY), are primary places to study prescription misuse. Study findings suggest that prescription drugs commonly seized in NY and LA are those most commonly misused in each city, and that variability in local markets of diverted drugs may impact frequency of misuse and modes of administration. Results on ages of initiation suggest that prescription drugs may serve as pathways to illicit drugs in some cases. Findings on drug substitution, drug combinations, and polydrug use indicate that prescription drugs in both NY and LA were frequently consumed as a part of a repertoire of misuse involving prescription drugs and illicit drugs.

\section{Abstract}

Background. Prescription drug misuse among young adults is increasingly viewed as a public health concern, yet most research has focused on student populations and excluded high-risk groups. Furthermore, research on populations who report recent prescription drug misuse is limited. This study examined patterns of prescription drug misuse among high-risk young adults in Los Angeles (LA) and New York (NY), which represent different local markets for illicit and prescription drugs.

Design and Methods. Between 2009 and 2011, 596 young adults (16 to 25 years old) who had misused prescription drugs within the past 90 days were interviewed in Los Angeles and New York. Sampling was stratified to enroll three groups of high-risk young adults: injection drug users (IDUs); homeless persons; and polydrug users.

Results. In both sites, lifetime history of receiving a prescription for an opioid, tranquilizer, or stimulant was high and commonly preceded misuse. Moreover, initiation of opioids occurred before heroin and initiation of prescription stimulants happened prior to illicit stimulants. NY participants more frequently misused oxycodone, heroin, and cocaine, and LA participants more frequently misused codeine, marijuana, and methamphetamine. Combining prescription and illicit drugs during drug using events was commonly reported in both sites. Opioids and tranquilizers were used as substitutes for other drugs, e.g., heroin, when these drugs were not available.

Conclusion. Patterns of drug use among high-risk young adults in Los Angeles and New York appear to be linked to differences in local markets in each city for illicit drugs and diverted prescription drugs.

\section{Introduction}

Prescription drugs have become established as primary substances of abuse alongside illicit drugs among young adults in the US over the past 10 years. ${ }^{1}$ Prescription opioids are the second most commonly misused drug after marijuana among persons aged 16 to 25 years old followed by cocaine, prescription tranquilizers, ecstasy, and prescription stimulants. ${ }^{2}$ Prescription drug misuse among young adults is increasingly viewed as a public health concern since it is associated with risk practices, such as sexual risk behaviors, ${ }^{3}$ polydrug use,${ }^{4}$ and injection drug use, ${ }^{5}$ and negative health outcomes, such as drug dependence and drug overdose. ${ }^{2}$

Most research on prescription drug misuse among young adults in the US has focused exclusively on student populations $s^{6-8}$ or utilized data from national sentinel surveys. ${ }^{9,10}$ In all of these studies of young adults, lifetime prevalence of the most commonly misused prescription drug - opioids - is no greater than $20 \%$ while current misuse (30- or 90-day) is below $5 \%$. While documenting important trends among lifetime misusers, these studies present limited data on young adults who are current misusers of prescription drugs - the population at the greatest risk for negative health outcomes.

Additionally, only a few studies have targeted or included high-risk groups of young adults, such as homeless persons, injection drug users, or polydrug users, into research examining prescription drug misuse. ${ }^{11-14}$ While originally focused on ecstasy or ketamine users, these studies report much higher rates of prescription drug misuse, e.g., lifetime opioid misuse exceeding $80 \%$, than studies targeting young adults who are housed, employed, or in school. Ultimately, studies that do not include high-risk groups may limit understanding of more complex patterns of prescription drug misuse.

Large metropolitan areas are primary places to study prescription misuse among diverse populations of young adults since current rates of drug use are highest in these areas. ${ }^{2}$ New York (NY) and Los Angeles (LA), the two largest metropolitan areas in the US ${ }^{15}$ with distinctly different cultural histories, local economies, and geographies, each represent particular local drug markets for both illicit and prescription drugs. A picture of each local drug market can be ascertained by comparing the most prevalent drugs (out of 100\%) recently seized and analyzed by law enforcement in LA and NY, respectively: marijuana (38\% vs $31 \%)$; cocaine ( $23.6 \%$ vs $38.9 \%)$; methamphetamine ( $16.1 \%$ vs $0.5 \%)$; heroin ( $5 \%$ vs $10.9 \%)$; hydrocodone (1.6\% vs $0.7 \%)$; oxycodone $(0.4 \%$ vs $3.5 \%)$; and alprozolam $(0.7 \%$ vs $2.6 \%) .{ }^{16}$ Furthermore, local heroin markets differ in these cities: Mexican tar heroin predominates in LA, a less pure form compared to South American powder heroin in NY.17 
In this analysis, we have two primary objectives. First, we aim to describe overall differences in lifetime and recent patterns of drug use among young adults in NY and LA who report recent misuse of prescription drugs. Based upon differences in local drug markets, we hypothesize that NY participants will report greater misuse of oxycodone products, such as Percocet and OxyContin, as well as alprozolam (Xanax), than LA, while LA participants will report greater misuse of hydrocodone products, such as Vicodin, than NY. Additionally, we hypothesize that NY participants will report greater use of cocaine and heroin than LA while LA participants will report greater use of methamphetamine and marijuana than NY. Second, we aim to describe the interrelationship among prescription and illicit drug misuse among a sample of high-risk young adults, regarding ages of initiation, patterns of polydrug use, and modes administration. We hypothesize that patterns of opioid misuse, for instance, will be associated with patterns of heroin use.

\section{Materials and Methods}

\section{Sampling}

The analysis is based upon a sample of 596 young adults interviewed in LA and NY between October 2009 and March 2011. Eligible participants were between 16 and 25 years old and had engaged in misuse of a prescription drug, i.e., opioid, tranquilizer, or stimulant, or any combination at least three times in the last 90 days. Misuse was defined as taking a prescription drug when they were not prescribed for you or that you took only for the experience or feeling it caused.2,18 Sampling was stratified to enroll three groups of high-risk young adults with different access to prescription drugs: injection drug users (IDUs), homeless persons, and polydrug users. IDUs were defined as injecting a drug within the past 90 days. Homeless persons were defined as not having a consistent residence within the past 90 days and/or sleeping on the street, in a park, or squat; injecting drugs in the past 90 days was an exclusion criteria for this group. Polydrug users were defined as having used two or more drugs (alcohol, illicit, and/or prescriptions) simultaneously within the past 90 days; being homeless or injecting drugs in the past 90 days were exclusion criteria for this group.

Participants were located using a combination of sampling strategies and data sources. Interviewers employed both targeted ${ }^{19}$ and chain-referral sampling ${ }^{20}$ in combination with recruitment data from earlier project phases ${ }^{5}$ to recruit young adults in natural settings, such as parks, streets, and neighborhoods. In New York, some participants were recruited from organizations serving homeless youth since homeless individuals meeting the enrollment criteria were more difficult to locate in natural settings. A brief screening tool was used to determine eligibility, and screened individuals received a $\$ 3$ gift card. Participants who qualified and were interviewed received a $\$ 25$ cash incentive. The study protocol was approved by institutional review boards at Drexel University, Children's Hospital Los Angeles, and National Development and Research Institutes, Inc.

Across the two sites, a total of 4432 individuals were screened and 831 (18.8\%) met the enrollment criteria. Among the 831 eligible young adults, 618 (74.4\%) agreed to participate and were interviewed. Twenty-two participants (3.6\%) were later excluded after it was revealed that they had not misused a prescription drug at least three times in the last 90 days, resulting in a final sample of 596. Based upon the stratification criteria, the final sample was comprised of 202 IDUs ( $\mathrm{LA}=100, \mathrm{NY}=102), 192$ homeless $(\mathrm{LA}=102, \mathrm{NY}=90)$ and 202 polydrug users $(\mathrm{LA}=101, \mathrm{NY}=101)$. In the final sample, the total number of currently homeless young adults was 355 since many in the IDU group were both IDUs and homeless.

\section{Data collection}

The study instrument was developed using Entryware software (Techneos Systems, Inc., Vancouver, Canada) and loaded onto laptop computers. The instrument was administered during face-to-face interviews with eligible participants by one of two interviewers at each site. Participants were provided with cards containing response options to facilitate standardization on some interview questions. Interviews were conducted in private offices or natural settings, such as fast food restaurants and parks. Interview data were recorded on laptop computers and with digital recorders.

\section{Measures}

The instrument incorporated questions from standardized measures, previous studies, ${ }^{14}$ and from topics that emerged during the formative qualitative phase. ${ }^{5}$ Demographic indicators, such as age, gender, and race, were assessed using conventional questions. The particular questions assessing drug use are detailed in Table 1.

\section{Data analysis}

Statistical analyses were conducted on cross-sectional data using SPSS version 18. Descriptive statistics were calculated overall and within site (LA and NY). In most cases, $t$-tests for continuous variables and Pearson's $\chi^{2}$-tests for binary variables compared differences between sites. In some cases, paired statistical tests, e.g., paired $t$-tests and McNemar tests, compared within-site means or frequencies.

Due to the large number of comparisons, all P-values have been adjusted using the false discovery rate controlling procedure described by Benjamini and Hochberg. ${ }^{21,22}$ The procedure involved ordering the nominal P-values associated with the entire set of comparisons, computing a Bonferroni-type adjusted critical value based on the ordered position of the test, and comparing the nominal p-value to the adjusted critical value. Using this procedure, 11 comparisons previously considered to be significant at $\mathrm{P}<0.05$ were excluded after adjustment for multiple comparisons. Adjusted significance levels are presented in the text and in Tables 2-6.

\section{Results}

\section{Demographics}

Sociodemographic variables are summarized in Table 2. Sample participants were typically in their early 20 s, white, male, and heterosexual. Over half reported being raised in a middle or upper class family. Most were currently homeless, unemployed, or had been arrested, while nearly half had health insurance or a history of drug treatment. About one-third were students. NY participants were more frequently female ( $38 \%$ vs $26 \%, \mathrm{P}<0.01$ ), white ( $64 \%$ vs $49 \%, \mathrm{P}<0.001$ ), employed $(27 \%$ vs $16 \%, \mathrm{P}<0.01)$ and had health insurance $(58 \%$ vs $37 \%, \mathrm{P}<0.001)$ than LA.

\section{Lifetime misuse, prescribed use, and ages of initiation-prescription and illicit drugs}

Frequencies of lifetime misuse, prescribed use, and ages of initiation for prescription and illicit drugs are presented in Table 3 , including a select set of illicit drugs that also may function as pain medications, tranquilizers, or stimulants. Among prescription drugs, opioids were the most frequently misused and prescribed. Regarding ages of prescribed use, stimulants were prescribed at the earliest age, followed by opioids and tranquilizers. Regarding ages of initiation into misuse, marijuana was initiated at the earliest age followed by opioids, stimulants, and tranquilizers. 
Table 1. Primary questions from survey instrument used to assess substance use and misuse in the statistical analysis.

Rey constructs Question

Lifetime history of receiving a prescription medication

Age of being prescribed a medication

Lifetime history of prescription drug misuse
Were you ever prescribed the following [pain pills, tranquilizers, stimulants] by a doctor for any past injury or health condition?

How old were you when you were first prescribed these medications?

Have you ever, even once, used any of the following [pain pills, tranquilizers, stimulants] when they were not prescribed for you or that you took only for the experience or feeling it caused?

Pain pill list: Vicodin, OxyContin, Percocet, etc.

Tranquilizer list: Xanax, Klonopin, Valium, etc.

Stimulant list: Adderall, Ritalin, Concerta, etc.

Age of misuse initiation of prescription drug How old were you the first time you used [pain pills, tranquilizers, stimulants] only for the experience or feeling they caused?

Lifetime history of misusing prescription drugs via

other modes of administration

Polydrug use with prescription drugs

Have you ever [sniffed, smoked, injected] a [pain pill, tranquilizer, stimulant]?

Which statement best describes how you've taken [pain pills, tranquilizers, stimulants] during the past 12 months: 1. By itself, without using any other substances before, during, or after; 2. In combination with one or more substances before, during or after.

Drug substitution with prescription drugs

Have you ever used a [pain pill, tranquilizer, stimulant] as a substitute for another drug that you wanted, but could not find? If yes, which drugs?

and

Have you ever used another drug as a substitute for a [pain pill, tranquilizer, stimulant] that you wanted, but could not find? If yes, which drugs?

Recent prescription drug misuse

How long has it been since you last used any [pain pills, tranquilizers, stimulants] that were not prescribed for you or that you took only for the experience or feeling it caused?

Lifetime history of using illicit drugs

Have you ever used [illicit drug list]?

List of illicit drugs: marijuana, LSD, ecstasy, heroin, cocaine, crack, crystal meth, ketamine. How old were you the first time you used [illicit drug list]?

Age of initiation of illicit drugs Have you ever injected any of the following [illicit drug list]?

Lifetime history of injecting illicit drugs

Recent illicit drug misuse

Lifetime history of receiving a prescription medication How long has it been since you last used [illicit drug list]?

Were you ever prescribed the following [pain pills, tranquilizers, stimulants] by a doctor for any past injury or health condition?

Age of being prescribed a medication

Lifetime history of prescription drug misuse

How old were you when you were first prescribed these medications?

Have you ever, even once, used any of the following [pain pills, tranquilizers, stimulants] when they were not prescribed for you or that you took only for the experience or feeling it caused?

Pain pill list: Vicodin, OxyContin, Percocet, etc.

Tranquilizer list: Xanax, Klonopin, Valium, etc.

Stimulant list: Adderall, Ritalin, Concerta, etc.

Age of misuse initiation of prescription drug $\quad$ How old were you the first time you used [pain pills, tranquilizers, stimulants] only for the experience or feeling they caused?

Lifetime history of misusing prescription

drugs via other modes of administration

Have you ever [sniffed, smoked, injected] a [pain pill, tranquilizer, stimulant]?

Polydrug use with prescription drugs

Which statement best describes how you've taken [pain pills, tranquilizers, stimulants] during the past 12 months:

1. By itself, without using any other substances before, during, or after;

2. In combination with one or more substances before, during or after.

Drug substitution with prescription drugs

Have you ever used a [pain pill, tranquilizer, stimulant] as a substitute for another drug that you wanted, but could not find? If yes, which drugs?

and

Have you ever used another drug as a substitute for a [pain pill, tranquilizer, stimulant] that you wanted, but could not find? If yes, which drugs?

Recent prescription drug misuse

How long has it been since you last used any [pain pills, tranquilizers, stimulants] that were not prescribed for you or that you took only for the experience or feeling it caused?

Lifetime history of using illicit drugs

Have you ever used [illicit drug list]?

List of illicit drugs: marijuana, LSD, ecstasy, heroin, cocaine, crack, crystal meth, ketamine.

How old were you the first time you used [illicit drug list]?

Age of initiation of illicit drugs

Have you ever injected any of the following [illicit drug list]?

How long has it been since you last used [illicit drug list]?

Recent illicit drug misuse 
Table 2. Demographics by site (Los Angeles and New York).

\begin{tabular}{|c|c|c|c|c|}
\hline Demographic factors & LA, $n=303(\%)$ & NY, $\mathrm{n}=293(\%)$ & Total, $\mathrm{n}=596,(\%)$ & $x^{2}$-test \\
\hline Age (mean \pm SD) & $20.91(2.11)$ & $20.81(2.00)$ & $20.86(2.06)$ & ns \\
\hline Gender ${ }^{\circ}$ & & & & $\chi^{2}(1)=9.4^{* *}$ \\
\hline Male & $213(70)$ & $177(61)$ & $390(66)$ & \\
\hline Female & $78(26)$ & $112(38)$ & $190(32)$ & \\
\hline Transgender & $12(4)$ & $3(1)$ & $15(2)$ & \\
\hline Race $^{\#}$ & & & & $\chi^{2}(1)=14.0^{* * *}$ \\
\hline Non-Hispanic White & $147(49)$ & $186(64)$ & $333(56)$ & \\
\hline Nonwhite: & $155(51)$ & $105(36)$ & $260(44)$ & \\
\hline Hispanic & $52(17)$ & $34(12)$ & $86(15)$ & \\
\hline Multiracial & $45(15)$ & $46(16)$ & $91(15)$ & \\
\hline Black/African American & $46(15)$ & $19(7)$ & $65(11)$ & \\
\hline Asian/Pacific Islander & $7(2)$ & $4(1)$ & $11(2)$ & \\
\hline Native American & $5(2)$ & $2(0.7)$ & $7(1)$ & \\
\hline Sexual identity & & & & ns \\
\hline Heterosexual & $210(70)$ & $183(63)$ & $393(66)$ & \\
\hline LGBT & $93(31)$ & $108(37)$ & $201(34)$ & \\
\hline Socioeconomic status growing up & & & & ns \\
\hline Poor or lower class & $140(47)$ & $124(43)$ & $264(45)$ & \\
\hline Middle or upper class & $161(54)$ & $167(57)$ & $328(55)$ & \\
\hline Completed high school/GED & $222(73)$ & $223(76)$ & $445(75)$ & ns \\
\hline Currently in school & $97(32)$ & $100(34)$ & $197(33)$ & ns \\
\hline Currently employed & $49(16)$ & $79(27)$ & $128(22)$ & $\chi^{2}(1)=10.3^{* *}$ \\
\hline Currently insured & $111(37)$ & $169(58)$ & $280(47)$ & $\chi^{2}(1)=28.6^{* * *}$ \\
\hline Currently homeless & $194(64)$ & $161(55)$ & $355(60)$ & ns \\
\hline History of arrest & $241(80)$ & $213(73)$ & $454(76)$ & ns \\
\hline History of jail time & $203(67)$ & $182(62)$ & $385(65)$ & ns \\
\hline Drug treatment & $123(41)$ & $127(43)$ & $250(42)$ & ns \\
\hline
\end{tabular}

${ }^{\circ} \chi^{2}$-test based on male $v$ f female only; ${ }^{\sharp} \chi^{2}$-test based on white $v s$ nonwhite only; LGBT, lesbian, gay, bisexual, or transgender; ns, non-significant; ${ }^{*} \mathrm{P}<0.05 ;{ }^{* *} \mathrm{P}<0.01 ;{ }^{* * *} \mathrm{P}<0.001$.

Nearly all of the significant between-site differences pertain to prescription or illicit stimulants. A significantly greater percentage of LA participants had been prescribed stimulants compared to NY ( $51 \%$ vs $39 \%$, $\mathrm{P}<0.05)$. Moreover, LA participants were prescribed stimulants at significantly earlier ages than $\mathrm{NY}(10.9$ vs 12.2 years, $\mathrm{P}<0.05)$ and initiated stimulant misuse at significantly earlier ages than NY (15.4 vs 16.2 years, $\mathrm{P}<0.05$ ). However, a significantly greater percentage of NY participants reported lifetime misuse of prescription stimulants than LA ( $84 \%$ vs $71 \%$, $\mathrm{P}<0.001$ ). The only significant illicit drug site difference pertained to methamphetamine: a significantly greater percentage of LA participants used methamphetamine compared to $\mathrm{NY}(61 \%$ vs $38 \%, \mathrm{P}<0.001)$.

Regarding within site differences (all results and paired $t$-tests not shown in Table 3), participants in NY and LA were prescribed stimulants at significantly earlier ages than their first misuse of stimulants $(12.4$ vs 15.4 years; paired $\mathrm{t}(102)=-6.68, \mathrm{P}<0.001 ; 11.0$ vs 14.7 years; paired $\mathrm{t}(125)=-9.36, \mathrm{P}<0.001$, respectively). Moreover, participants in both NY and LA initiated misuse of prescription stimulants at significantly earlier ages than cocaine, methamphetamine, and ecstasy (16.1 vs 17.1 years; paired $\mathrm{t}(209)=-5.95, \mathrm{P}<0.001 ; 15.2$ vs 16.9 years; paired $\mathrm{t}(190)=-7.63 \mathrm{P}<0.001$, respectively). Among those prescribed opioids, no significant differences emerged between age of prescribed use and age of first misuse. In both NY and LA, participants initiated misuse of opioids at significantly earlier ages than heroin (14.8 vs 17.5 years; paired $\mathrm{t}(149)=-13.52, \mathrm{P}<0.001 ; 14.6$ vs 17.5 years; paired $\mathrm{t}(137)=$ $11.43, \mathrm{P}<0.001$, respectively).

\section{Specific prescription drugs misused}

Frequencies of lifetime misuse of specific types of prescription drugs, which may provide insights into local prescribing practices and drug diversion, are presented in Table 4. Participants reported lifetime misuse of a wide range of prescription opioids of differing potencies. The most frequently misused opioids included hydrocodone, oxycodone, and codeine. A significantly greater percentage of NY participants reported misuse of any oxycodone product compared to LA (89\% vs $71 \%, \mathrm{P}<0.001$ ), whereas a significantly greater percentage of LA participants reported misuse of codeine compared to NY ( $62 \%$ vs $51 \%$, $\mathrm{P}<0.05$ ). Vicodin was the most frequently misused formulation of hydrocodone, and OxyContin was the most frequently misused formulation of oxycodone. Except for Percodan, NY participants reported significantly more misuse of all formulations and combinations of oxycodone than LA, e.g., Percocet ( $73 \%$ vs $40 \%, \mathrm{P}<0.001)$. Within sites, LA participants reported significantly more misuse of any hydrocodone than any oxycodone $\left(87 \%\right.$ vs $71 \%$; McNemar $\left.\chi^{2}(1)=22.0, \mathrm{P}<0.001\right)$. Misuse of any opioid substitution medications, such as methadone or buprenorphine, was reported by less than half of all participants, while NY participants reported significantly more misuse of Suboxone (34\% vs $17 \%, \mathrm{P}<0.001)$ and Subutex $(14 \%$ vs $6 \%, \mathrm{P}<0.01)$ than LA.

Xanax was the most frequently misused tranquilizer, followed by Valium and Klonopin. NY participants reported significantly more misuse of Klonopin ( $60 \%$ vs 41\%, $\mathrm{P}<0.001)$, while LA participants reported significantly more misuse of Seroquel $(50 \%$ vs $38 \%, \mathrm{P}<0.05)$. Adderall was the most frequently misused stimulant followed by Ritalin, Concerta, and Dexedrine. NY participants reported significantly more misuse of Adderall (75\% vs $60 \%, \mathrm{P}<0.001)$, Ritalin $(51 \%$ vs $41 \%$, $\mathrm{P}<0.05)$, and Concerta (23\% vs $15 \%, \mathrm{P}<0.05)$ than $\mathrm{LA}$.

*There are notable differences in the potencies of prescription opioids. For instance, oxycodone is seven to twelve times stronger than codeine, while hydrocodone is two to eight times stronger than codeine assuming similar modes of administration. ${ }^{23}$ 


\section{Prescription drug using practices and risk behaviors}

Frequencies of lifetime modes of administering specific categories of prescription drugs and illicit drugs are presented in Table 5 . Participants administered prescription drugs via a range of modalities other than swallowing: snorting was more commonly reported than either injecting or smoking. Opioids were more frequently sniffed, smoked, and injected than either stimulants or tranquilizers. NY participants were significantly more likely to sniff opioids (68\% vs $53 \%$, $\mathrm{P}<0.001)$ and stimulants $(58 \%$ vs $43 \%, \mathrm{P}<0.01)$ than LA. LA participants more commonly smoked all three types of drugs compared to NY participants, but only opioids exhibited a significant difference (27\% vs $14 \%, \mathrm{P}<0.001)$. No site differences regarding injecting prescription drugs were observed; overall, approximately one-quarter of participants ever injected a prescription opioid.

Comparing histories of injecting illicit drugs revealed more site differences. NY participants reported significantly greater frequency of injecting heroin ( $41 \%$ vs $30 \%, \mathrm{P}<0.05)$, cocaine ( $32 \%$ vs $17 \%, \mathrm{P}<0.001$ ), and crack $(16 \%$ vs $9 \%, \mathrm{P}<0.05)$, while LA participants reported significantly greater frequency of injecting methamphetamine $(27 \%$ vs $12 \%$, $\mathrm{P}<0.001$ ). Comparing injecting heroin and opioids within sites, NY participants reported significantly greater frequency of injecting heroin than opioids ( $41 \%$ vs $29 \%, \mathrm{P}<0.01$ ), whereas no significant differences in LA were observed.

Polydrug use, or combining drugs during a drug-using event, was a common feature of prescription drug misuse: a majority of misusers of both opioids and tranquilizers reported that combining these drugs with other drugs was typical in the past 12 months. No site differences were observed. Substituting with prescription drugs, e.g., prescription opioids, when other drugs, e.g., heroin, could not be located was commonly reported: half of the sample's opioid users reported using an opioid as a substitute, though fewer tranquilizer and stimulant users reported this practice. No site differences were found. Substituting with other drugs when prescription drugs could not be found was less frequently reported. However, among those that did, LA participants reported significantly greater frequency of using another drug as a substitute for opioids ( $36 \%$ vs $27 \%, \mathrm{P}<0.05)$, tranquilizers $(28 \%$ vs $19 \%$, $\mathrm{P}<0.05)$, and stimulants $(22 \%$ vs $13 \%, \mathrm{P}<0.05)$ than $\mathrm{NY}$ participants.

\section{Current misuse of prescription and illicit drugs}

Frequencies of 90-day misuse of prescription and illicit drugs are presented in Table 6. All participants misused at least one prescription drug within the past 90-days (an enrollment criterion for the study). Opioids and tranquilizers were the most frequently misused, followed by stimulants. No significant differences were found by site. Participants also reported frequent use of illicit drugs in the past 90 days. As predicted, NY participants reported significantly greater use of heroin $(40 \%$ vs $29 \%, \mathrm{P}<0.01)$ and cocaine $(59 \%$ vs $36 \%, \mathrm{P}<0.001)$, while LA participants reported significantly greater use of marijuana ( $97 \%$ vs $90 \%, \mathrm{P}<0.001)$ and methamphetamine $(40 \%$ vs $12 \%, \mathrm{P}<0.001)$.

Participants reported co-occurring misuse of prescription and illicit

Table 3. Lifetime misuse/use of prescription/illicit drugs, drugs prescribed, and age of initiation by site (Los Angeles and New York).

\begin{tabular}{|c|c|c|c|c|}
\hline Lifetime misuse/use & LA, $n=303(\%)$ & $N Y, n=293(\%)$ & Total, $\mathrm{n}=596(\%)$ & $\chi^{2}$-test \\
\hline \multicolumn{5}{|l|}{ Misuse of prescription drugs } \\
\hline Opioids & $292(96)$ & $284(97)$ & $576(97)$ & ns \\
\hline Tranquilizers & $266(88)$ & $267(91)$ & $533(89)$ & ns \\
\hline Stimulants & $215(71)$ & $247(84)$ & $462(78)$ & $\chi^{2}(1)=15.2^{* * *}$ \\
\hline Lifetime misuse of all 3 & $189(62)$ & $222(76)$ & $411(69)$ & $\chi^{2}(1)=12.5^{* *}$ \\
\hline \multicolumn{5}{|l|}{ Drugs prescribed } \\
\hline Opioids & $232(77)$ & $202(69)$ & 434 (73) & ns \\
\hline Tranquilizers & $138(46)$ & $133(45)$ & $271(46)$ & ns \\
\hline Stimulants & $154(51)$ & $115(39)$ & $269(45)$ & $\chi^{2}(1)=8.1^{*}$ \\
\hline Any of 3 & $274(90)$ & $248(85)$ & $522(88)$ & ns \\
\hline \multicolumn{5}{|l|}{ Use of illicit drugs } \\
\hline Marijuana & $302(100)$ & $292(99)$ & $593(100)$ & ns \\
\hline Ecstasy & $257(85)$ & $245(84)$ & $502(84)$ & ns \\
\hline Cocaine & $244(81)$ & $256(87)$ & $500(84)$ & ns \\
\hline Methamphetamine & $186(61)$ & $111(38)$ & $297(50)$ & $\chi^{2}(1)=32 . .^{* * *}$ \\
\hline Heroin & $140(46)$ & $152(52)$ & $292(49)$ & ns \\
\hline Crack & $132(44)$ & $118(40)$ & $250(42)$ & ns \\
\hline Age of initiation & LA (mean, SD) & NY (mean, SD) & Total (mean, SD) & $\begin{array}{c}t \text {-test } \\
t(d f), \text { P-value }\end{array}$ \\
\hline \multicolumn{5}{|l|}{ Misuse of prescription drugs } \\
\hline Stimulants & $15.4(3.5)$ & $16.2(2.5)$ & $15.8(3.1)$ & $\mathrm{t}(460)=-2.7^{*}$ \\
\hline Opioids & $15.6(3.1)$ & $15.5(2.4)$ & $15.5(2.8)$ & ns \\
\hline Tranquilizers & $16.3(3.0)$ & $16.3(2.7)$ & $16.3(2.9)$ & ns \\
\hline \multicolumn{5}{|l|}{ First prescribed } \\
\hline Stimulants & $10.9(4.4)$ & $12.2(4.6)$ & $11.5(4.5)$ & $t(267)=-2.4^{*}$ \\
\hline Opioids & $15.4(3.9)$ & $15.4(3.8)$ & $15.4(3.8)$ & ns \\
\hline Tranquilizers & $16.0(3.6)$ & $16.2(3.2)$ & $16.1(3.4)$ & ns \\
\hline \multicolumn{5}{|l|}{ Use of illicit drugs } \\
\hline Marijuana & $13.3(3.1)$ & $13.6(2.4)$ & $13.4(2.8)$ & ns \\
\hline Cocaine & $16.7(2.6)$ & $16.6(2.3)$ & $16.6(2.4)$ & ns \\
\hline Methamphetamine & $16.9(3.3)$ & $17.3(2.6)$ & $17.1(3.0)$ & ns \\
\hline Ecstasy & $17.2(2.6)$ & $17.2(2.1)$ & $17.2(2.4)$ & ns \\
\hline Heroin & $17.5(2.6)$ & $17.5(2.3)$ & $17.5(2.4)$ & ns \\
\hline Crack & $17.4(2.6)$ & $17.9(2.4)$ & $17.6(2.5)$ & ns \\
\hline
\end{tabular}

ns, non-significant; ${ }^{*} \mathrm{P}<0.05 ;{ }^{* *} \mathrm{P}<0.01 ;{ }^{* * *} \mathrm{P}<0.001$. 
drugs within the past 90 days, which may indicate patterns of polydrug use or drug substitution. The co-occurrence of opioids and tranquilizers was most frequent. No significant differences by site were found. Regarding illicit drugs, the three most frequently reported co-occurrences were tranquilizers and cocaine, opioids and heroin, and tranquilizers and ecstasy. While multiple significant site differences were found, the largest differences involved LA participants reporting more frequent combinations of tranquilizers and methamphetamine $(33 \%$ vs $9 \%, \mathrm{P}<0.001)$ and NY participants reporting more frequent combinations of tranquilizers and cocaine $(47 \%$ vs $29 \%, \mathrm{P}<0.001)$. Additionally, NY participants reported more frequent combinations of stimulants and cocaine $(32 \%$ vs $19 \%, \mathrm{P}<0.01)$.

\section{Discussion}

This is the first study to our knowledge that compares patterns of prescription and illicit drug misuse in two large urban areas among diverse samples of young adults who are current misusers of prescription drugs. Lifetime misuse of particular prescription drugs and recent use of illicit drugs closely tracked drug seizure data and largely confirmed our first hypotheses: more frequent misuse of oxycodone, heroin, and cocaine in NY, and more frequent use of marijuana and methamphetamine in LA. ${ }^{16}$ Hydrocodone was more frequently misused than oxycodone in LA, which is also consistent with monitoring data. ${ }^{16}$ These findings suggest that prescription drugs commonly seized in NY and LA are in fact those most commonly misused in each city, and that variability in local markets of diverted drugs may impact frequency of misuse.

Moreover, variations in local drug markets may be factors in explaining differences in modes of administrating opioids and heroin in each city. For instance, Mexican heroin found in LA is frequently in tar form, whereas Colombian heroin found in NY is commonly in powder form. ${ }^{24}$ In NY, where sniffing powder heroin is common, ${ }^{25} \mathrm{NY}$ participants more frequently sniffed opioids than LA participants. In LA, where smoking tar heroin is common, ${ }^{26}$ LA participants more frequently smoked opioids than NY participants. These results suggest that participants may have transferred local practices for administering different forms of heroin in each site, i.e., sniffing and smoking, towards administering prescription opioids. These findings provide support for our second hypothesis which proposed an interrelationship between opioid and heroin use.

Furthermore, our results suggest the differences in heroin markets - both supply and form - did not impact lifetime frequency of injecting prescription opioids. NY participants reported more frequent lifetime heroin use, 90-day use, and heroin injection than LA. However, no dif-

Table 4. Specific prescription drug type misused by site (Los Angeles and New York).

\begin{tabular}{|c|c|c|c|c|}
\hline Type of prescription drug & $\mathrm{LA}, \mathrm{n}=303(\%)$ & $N Y, n=293(\%)$ & Total, $\mathrm{n}=596,(\%)$ & $\chi^{2}$-test \\
\hline \multicolumn{5}{|l|}{ Opioids } \\
\hline Any hydrocodone & $263(87)$ & $246(84)$ & $509(85)$ & ns \\
\hline Vicodin (hydrocodone) & $257(85)$ & $234(80)$ & $491(82)$ & ns \\
\hline Lortab (hydrocodone) & $89(29)$ & $83(28)$ & $172(29)$ & ns \\
\hline Norco (hydrocodone) & $31(10)$ & $28(10)$ & $59(10)$ & ns \\
\hline 2 or more hydrocodones & $93(31)$ & $85(29)$ & $178(30)$ & ns \\
\hline Any oxycodone & $216(71)$ & $261(89)$ & $477(80)$ & $\chi^{2}(1)=29.5^{* * *}$ \\
\hline Oxycontin (oxycodone) & $196(65)$ & $220(75)$ & $416(70)$ & $\chi^{2}(1)=7.6^{*}$ \\
\hline Percocet (oxycodone) & $120(40)$ & $215(73)$ & $335(56)$ & $\chi^{2}(1)=69.0^{* * *}$ \\
\hline Percodan (oxycodone) & $41(14)$ & $44(15)$ & $85(14)$ & ns \\
\hline Roxicet (oxycodone) & $32(11)$ & $60(21)$ & $92(15)$ & $\chi^{2}(1)=11.2^{* *}$ \\
\hline 2 or more oxycodones & $114(38)$ & $183(63)$ & $297(50)$ & $\chi^{2}(1)=36.7^{* * *}$ \\
\hline Any opioid therapy & $121(40)$ & $131(45)$ & $252(42)$ & ns \\
\hline Methadone & $106(35)$ & $103(35)$ & $209(35)$ & ns \\
\hline Suboxone (buprenorphine/naloxone) & $51(17)$ & $101(34)$ & $152(25)$ & $\chi^{2}(1)=24.4^{* * *}$ \\
\hline Subutex (buprenorphine) & $19(6)$ & $41(14)$ & $60(10)$ & $\chi^{2}(1)=9.8^{* *}$ \\
\hline 2 or more opioid therapy & $40(13)$ & $78(26)$ & $118(20)$ & $\chi^{2}(1)=16.9^{* * *}$ \\
\hline Codeine & $188(62)$ & $150(51)$ & $338(57)$ & $\chi^{2}(1)=7.1^{*}$ \\
\hline Morphine & $144(48)$ & $125(43)$ & $269(45)$ & ns \\
\hline Dilaudid (hydromorphone) & $61(20)$ & $67(23)$ & $128(22)$ & ns \\
\hline Fentanyl & $47(16)$ & $73(25)$ & $120(20)$ & $\chi^{2}(1)=8.2^{*}$ \\
\hline Demerol (meperidine) & $57(19)$ & $41(14)$ & $98(16)$ & ns \\
\hline Other & $44(15)$ & $48(16)$ & $92(15)$ & ns \\
\hline \multicolumn{5}{|l|}{ Tranquilizers } \\
\hline Xanax (alprozolam) & $222(73)$ & $234(80)$ & $456(77)$ & ns \\
\hline Valium (diazepam) & $157(52)$ & $169(58)$ & $326(55)$ & ns \\
\hline Klonopin (clonazepam) & $124(41)$ & $177(60)$ & $301(51)$ & $\chi^{2}(1)=23.1^{* * *}$ \\
\hline Seroquel (quetiapine) & $150(50)$ & $110(38)$ & $260(44)$ & $\chi^{2}(1)=8.5^{*}$ \\
\hline Ativan (lorazepam) & $58(19)$ & $71(24)$ & $129(22)$ & ns \\
\hline Other & $63(21)$ & $73(25)$ & $136(23)$ & ns \\
\hline \multicolumn{5}{|l|}{ Stimulants } \\
\hline Adderall (amphetamine and dextroamphetamine) & $183(60)$ & $220(75)$ & $403(68)$ & $\chi^{2}(1)=15.2^{* * *}$ \\
\hline Ritalin (methylphenidate) & $123(41)$ & $148(51)$ & $271(46)$ & $\chi^{2}(1)=6.1^{*}$ \\
\hline Concerta (methylphenidate) & $45(15)$ & $67(23)$ & $112(19)$ & $\chi^{2}(1)=6.4^{*}$ \\
\hline Dexedrine (dextroamphetamine) & $34(11)$ & $52(18)$ & $86(14)$ & ns \\
\hline Other & $25(8)$ & $35(12)$ & $60(10)$ & ns \\
\hline
\end{tabular}

ns, non-significant; ${ }^{*} \mathrm{P}<0.05 ;{ }^{* *} \mathrm{P}<0.01 ;{ }^{* * *} \mathrm{P}<0.001$. 
Table 5. Lifetime illicit and prescription drug misuse practices by site (Los Angeles and New York).

\begin{tabular}{|c|c|c|c|c|}
\hline Drug using practices & LA, n=303 (\%) & NY, n=293 (\%) & Total, $\mathrm{n}=596(\%)$ & $x^{2}$-test \\
\hline $\begin{array}{l}\text { Ever sniff Rx drugs } \\
\text { Any } \\
\text { Opioids } \\
\text { Tranquilizers } \\
\text { Stimulants }\end{array}$ & $\begin{array}{l}204(67) \\
159(53) \\
130(43) \\
131(43)\end{array}$ & $\begin{array}{l}237(81) \\
198(68) \\
140(48) \\
169(58)\end{array}$ & $\begin{array}{l}441(74) \\
357(60) \\
270(45) \\
300(50)\end{array}$ & $\begin{array}{c}\chi^{2}(1)=15.6^{* * *} \\
\chi^{2}(1)=14.1^{* * *} \\
\text { ns } \\
\chi^{2}(1)=12.4^{* *}\end{array}$ \\
\hline $\begin{array}{l}\text { Ever smoke Rx drugs }{ }^{\#} \\
\text { Any } \\
\text { Opioids } \\
\text { Tranquilizers } \\
\text { Stimulants }\end{array}$ & $\begin{array}{r}95(31) \\
82(27) \\
27(9) \\
19(6)\end{array}$ & $\begin{array}{r}59(20) \\
41(14) \\
15(5) \\
14(5)\end{array}$ & $\begin{array}{r}154(26) \\
123(21) \\
42(7) \\
33(6)\end{array}$ & $\begin{array}{c}\chi^{2}(1)=9.8^{* *} \\
\chi^{2}(1)=15.5^{* * *} \\
\text { ns } \\
\text { ns }\end{array}$ \\
\hline $\begin{array}{l}\text { Ever inject Rx drugs } \\
\text { Any } \\
\text { Opioids } \\
\text { Tranquilizers } \\
\text { Stimulants }\end{array}$ & $\begin{array}{r}77(25) \\
72(24) \\
33(11) \\
16(5)\end{array}$ & $\begin{array}{r}84(29) \\
82(28) \\
30(10) \\
25(9)\end{array}$ & $\begin{array}{r}161(27) \\
154(26) \\
63(11) \\
41(7)\end{array}$ & $\begin{array}{l}\text { ns } \\
\text { ns } \\
\text { ns } \\
\text { ns }\end{array}$ \\
\hline $\begin{array}{l}\text { Ever inject illicit drugs } \\
\text { Heroin } \\
\text { Cocaine } \\
\text { Crack } \\
\text { Methamphetamine }\end{array}$ & $\begin{array}{r}91(30) \\
51(17) \\
26(9) \\
81(27)\end{array}$ & $\begin{array}{r}121(41) \\
94(32) \\
47(16) \\
36(12)\end{array}$ & $\begin{array}{r}212(36) \\
145(24) \\
73(12) \\
117(20) \\
\end{array}$ & $\begin{array}{c}\chi^{2}(1)=8.1^{*} \\
\chi^{2}(1)=18.6^{* * *} \\
\chi^{2}(1)=7.6^{*} \\
\chi^{2}(1)=19.9^{* * *}\end{array}$ \\
\hline $\begin{array}{l}\text { Polydrug use in conjuncti } \\
\text { Opioids } \\
\text { Tranquilizers } \\
\text { Stimulants }\end{array}$ & $\begin{array}{r}191(71) \\
169(70) \\
79(53)\end{array}$ & $\begin{array}{l}201(78) \\
177(74) \\
106(61)\end{array}$ & $\begin{array}{l}392(74) \\
346(72) \\
185(57)\end{array}$ & $\begin{array}{l}\text { ns } \\
\text { ns } \\
\text { ns }\end{array}$ \\
\hline $\begin{array}{l}\text { Ever used Rx as substitut } \\
\text { Opioids } \\
\text { Tranquilizers } \\
\text { Stimulants }\end{array}$ & $\begin{array}{r}151(50) \\
104(34) \\
65(22)\end{array}$ & $\begin{array}{r}149(51) \\
112(38) \\
74(25)\end{array}$ & $\begin{array}{l}300(50) \\
216(36) \\
139(23)\end{array}$ & $\begin{array}{l}\text { ns } \\
\text { ns } \\
\text { ns }\end{array}$ \\
\hline $\begin{array}{l}\text { Ever used another drug a } \\
\text { Opioids } \\
\text { Tranquilizers } \\
\text { Stimulants }\end{array}$ & $\begin{array}{r}110(36) \\
86(28) \\
65(22)\end{array}$ & $\begin{array}{l}80(27) \\
55(19) \\
37(13)\end{array}$ & $\begin{array}{l}190(32) \\
141(24) \\
102(17)\end{array}$ & $\begin{array}{l}\chi^{2}(1)=5.6^{*} \\
\chi^{2}(1)=7.6^{*} \\
\chi^{2}(1)=8.2^{*}\end{array}$ \\
\hline
\end{tabular}

Table 6. 90-day misuse of illicit and prescription drugs by site (Los Angeles and New York.)

\begin{tabular}{|c|c|c|c|c|}
\hline Drug type(s) & $\mathrm{LA}, \mathrm{n}=303(\%)$ & NY, n=293 (\%) & Total, $\mathrm{n}=596(\%)$ & Difference test \\
\hline \multicolumn{5}{|l|}{ 90-day misuse of Rx drugs } \\
\hline Opioids & $246(82)$ & $229(78)$ & $475(80)$ & ns \\
\hline Tranquilizers & $213(71)$ & $209(71)$ & $422(71)$ & ns \\
\hline Stimulants & $122(41)$ & $143(49)$ & $265(45)$ & ns \\
\hline \multicolumn{5}{|l|}{ 90-day use of illicit drugs } \\
\hline Marijuana & $295(97)$ & $263(90)$ & $558(94)$ & $\chi^{2}(1)=16.0^{* * *}$ \\
\hline Cocaine & $109(36)$ & $174(59)$ & $283(47)$ & $\chi^{2}(1)=32.5^{* * *}$ \\
\hline Ecstasy & $130(43)$ & $106(36)$ & $236(40)$ & ns \\
\hline Heroin & $87(29)$ & $119(40)$ & $206(35)$ & $\chi^{2}(1)=9.4^{* *}$ \\
\hline Methamphetamine & $120(40)$ & $34(12)$ & $154(26)$ & $\chi^{2}(1)=61.3^{* * *}$ \\
\hline Crack & $61(20)$ & $50(17)$ & $111(19)$ & ns \\
\hline \multicolumn{5}{|l|}{ Rx combinations } \\
\hline Opioids \& tranquilizers & $175(58)$ & $167(57)$ & $342(57)$ & ns \\
\hline Opioids \& stimulants & $85(28)$ & $100(34)$ & $185(31)$ & ns \\
\hline Tranquilizers \& stimulants & $90(30)$ & $97(33)$ & $187(31)$ & ns \\
\hline \multicolumn{5}{|l|}{$\mathrm{Rx}$ and illicit combinations } \\
\hline Opioids \& heroin & $84(28)$ & $111(38)$ & $195(33)$ & $\chi^{2}(1)=7.0^{*}$ \\
\hline Tranquilizers \& heroin & $75(25)$ & $96(32)$ & $171(29)$ & ns \\
\hline Stimulants \& cocaine & $59(19)$ & $93(32)$ & $152(25)$ & $\chi^{2}(1)=11.8^{* *}$ \\
\hline Stimulants \& ecstasy & $63(21)$ & $61(21)$ & $124(21)$ & ns \\
\hline Stimulants \& methamphetamine & $51(17)$ & $23(8)$ & $74(12)$ & $\chi^{2}(1)=11.1^{* *}$ \\
\hline Tranquilizers \& cocaine & $89(29)$ & $139(47)$ & $228(38)$ & $\chi^{2}(1)=20.6^{* * *}$ \\
\hline Tranquilizers \& ecstasy & $100(33)$ & $89(30)$ & $189(32)$ & ns \\
\hline Tranquilizers \& methamphetamine & $101(33)$ & $27(9)$ & $128(21)$ & $\chi^{2}(1)=102.9^{* * *}$ \\
\hline
\end{tabular}

ns, non-significant; ${ }^{*} \mathrm{P}<0.05 ;{ }^{* *} \mathrm{P}<0.01 ;{ }^{* * *} \mathrm{P}<0.001$. 
ferences were found in lifetime history of injecting opioids - about onequarter of participants in both sites had injected opioids. In other words, greater use of heroin in NY- including injection - did not translate into more frequent injection of prescription opioids in NY compared to LA.

While 90-day opioid misuse did not vary between sites, lifetime data suggest greater misuse and availability of more potent opioids in NY, such as oxycondone, fentanyl, and buprenorphine, than in LA. Significantly, the use of more potent prescription opioids in NY coincided with a more robust heroin market in NY. Previous research indicated that potent opioids were particularly useful towards self-medicating for heroin withdrawal as well as functioning as a substitute when heroin was unavailable. ${ }^{5}$ While prior studies report opioid misuse in cities where heroin is scarce, ${ }^{27,28}$ these results indicate active misuse of opioids in cities where heroin is frequently available. ${ }^{29}$ The fact that young adults accessed both opioids and heroin, for instance, suggests the potential for overlapping markets for prescription and illicit drugs, which is in contrast to the conventional view of separate markets. ${ }^{30}$

Findings on drug substitution, drug combinations, and polydrug use indicate that prescription drugs in both NY and LA were frequently consumed as a part of a broader repertoire of misuse involving prescription drugs and illicit drugs. ${ }^{11,14}$

Opioids and tranquilizers were used as substitutes for other drugs when these drugs were not available. The most common drug combinations reported in the past 90 days were opioids and tranquilizers, cocaine and tranquilizers, and heroin and opioids. Qualitative research among young IDUs suggests that particular drug combinations, such as opioids and tranquilizers, are frequently used simultaneously or consecutively during polydrug using events. ${ }^{5}$ Significantly, the misuse of prescription drugs in polydrug combinations presents a greater chance for both fatal and non-fatal overdose. ${ }^{31,32}$

Lifetime history of receiving a prescription for an opioid, tranquilizer, or stimulant was high (88\%), particularly for opioids (73\%). ${ }^{33}$ In both sites, participants were prescribed stimulants at significantly earlier ages than the age of first misuse, suggesting that participants used these drugs as prescribed for an extended period before misusing. ${ }^{34}$ In contrast, initiation into misuse of opioids and receiving a prescription for an opioid occurred at approximately the same age in both sites. In these cases, several factors may have played a role in initiation, including developing a physical dependence on the prescribed drug, enjoying the novel psychoactive features of the prescribed drug, or inadequate management of pain. $5,35,36$ Overall, initiation of prescription drugs occurred during the early to mid-teens, after marijuana and before other illicit substances. In particular, initiation of opioids occurred before heroin and initiation of prescription stimulants happened prior to illicit stimulants. These findings on ages of initiation, in combination with the high percentage of participants who used heroin, cocaine, and methamphetamine, suggest that prescription drugs may serve as pathways to illicit drugs in some cases. $5,37,38$

Overall, these results suggest that metropolitan drug seizure data ${ }^{16}$ may be accurate predictors of the most frequently misused prescription and illicit drugs among certain subgroups of users in some cities. This information could be useful for the other 20 cities where this data is available in confirming that existing programs are targeting the most commonly misused drugs or developing new types of drug treatment programs for both prescription and illicit drugs. Future studies should conduct longitudinal research on young adults in different cities or regions to examine local drug markets and determine how fluctuations in local drug markets impact patterns of illicit and prescription drug misuse, including use of local drug treatment services. Findings could guide drug treatment providers towards developing programs for future young adult clients who may present increasingly complex histories of drug use.
This study has some limitations. First, results are based upon crosssectional data. Hence, only associations between variables can be determined rather than causal relationships. Second, the sample is comprised of young adults who were currently homeless and/or had engaged in high-risk behaviors, such as injection drug use or polydrug use, in NY and LA. Consequently, the results may not generalize to the larger population of young adults who are housed or who do not engage in these risk behaviors, or to high-risk young adults in other cities. Nonetheless, the sample represents an important subgroup of young adults who should be included in future studies to better describe the spectrum of prescription drug misuse.

In conclusion, patterns of prescription drug misuse among high-risk young adults in LA and NY appear to conform to and be shaped by differences in local markets for illicit drugs in each city. Our findings indicate that current misuse of prescription drugs in both cities encompasses a broad range of practices, such as sniffing, injecting, polydrug use, and drug substitution, and involves frequent misuse of illicit substances. Initiation into prescription drug misuse was often preceded by being prescribed one or more types of prescription drugs, which was then followed by initiating illicit drugs with similar psychotropic effects. Our results suggest that drug treatment providers may anticipate increasingly complex patterns of prescription and illicit drug use among newly enrolled young adult clients.

Correspondence: Dr. Stephen E. Lankenau, Drexel University, School of Public Health, Department of Community Health and Prevention, 1505 Race Street, $11^{\text {th }}$ floor, Philadelphia, PA 19102, USA.

Tel. +1.215.7622570 - Fax: +1.215 .7624088 .

E-mail: lankenau@drexel.edu

Key words: prescription drug misuse; illicit drugs; high-risk young adults. Acknowledgements: this research was supported by a grant from the National Institute of Drug Use (DA021299).

Contribution: SL, study design, first drafting of the manuscript; SS, KS, AK, JJB, statistical analyses. All authors provided substantive comments to earlier drafts and have approved the final manuscript.

Conflict of interest: the authors report no conflicts of interest.

Received for publication: 11 November 2011.

Accepted for publication: 23 December 2011.

(C) Copyright S.E. Lankenau et al., 2012

Licensee PAGEPress, Italy

Journal of Public Health Research 2012; 1:e6

doi:10.4081/jphr.2012.e6

This work is licensed under a Creative Commons Attribution NonCommercial 3.0 License (CC BY-NC 3.0).

\section{References}

1. Johnston LD, O'Malley PM, Bachman JG, Schulenberg JE. Monitoring the future national results on adolescent drug use: Overview of key findings, 2010. Institute for Social Research, The University of Michigan, Ann Arbor, USA. Available from: http://monitoringthefuture.org/pubs/monographs/mtf-overview2010.pdf

2. Substance Abuse and Mental Health Services Administration. Results from the 2009 National Survey on Drug Use and Health: Volume I. Summary of National Findings. Office of Applied Studies. 2010; NSDUH Series H-38A, HHS Publication No. SMA 10-4856. Rockville, MD, USA. Available from: http:/www.samhsa.gov/data/ NSDUH/2k9NSDUH/2k9Results.htm

3. Benotsh EG, Koester S, Luckman D, et al. Non-medical use of pre- 
scription drugs and sexual risk behavior in young adults. Addict Behav 2011;36:152-5.

4. Quintero G. Rx for a party: a qualitative analysis of recreational pharmaceutical use in a collegiate setting. J Am Coll Health 2009; 58:64-70.

5. Lankenau SE, Teti M, Silva K, Bloom JJ, Harocopos, A., Treese, M. Initiation into prescription opioid misuse amongst young injection drug users. Int J Drug Policy 2012;23:37-44.

6. Arria AM, Calderina KM, O'Grady KE, et al. Drug exposure opportunities and use patterns among college students: results from a longitudinal cohort study. Subst Abus 2008; 29:19-38.

7. Ford JA, Arrastia MC. Pill-poppers and dopers: a comparison of nonmedical prescription drug use and illicit/drug use among college student. Addict Behav 2008; 33:934-41.

8. Teter CJ, Falone AE, Cranford JA, Boyd CJ, McCabe SE. Nonmedical use of prescription stimulants and depressed mood among college students: frequency and routes of administration. J Subst Abuse Treat 2010;38:292-8.

9. McCabe SE, Cranford JA, Boyd CJ. The relationship between pastyear drinking behaviors and nonmedical use of prescription drugs: prevalence of co-occurrence in a national sample. Drug Alcohol Depend. 2006;84:281-8.

10. Wu LT, Woody GE, Yang C, Blazer DG. Subtypes of nonmedical opioid users: results from the national epidemiologic survey on alcohol and related conditions. Drug Alcohol Depend 2010; 112:69-80.

11. Daniulaityte R, Falck RS, Wang J, Carlson RG. Illicit use of pharmaceutical opioids among young polydrug users in Ohio. Addict Behav 2009;34:649-53.

12. Kurtz SP, Inciardi JA, Surratt HL, Cottler L. Prescription drug abuse among ecstasy users in Miami. J Addict Dis 2005;24:1-16.

13. Kelly BC, Parsons JT. Prescription drug misuse among club drugusing young adults. Am J Drug Alcohol Abuse 2007;33:875-84.

14. Lankenau SE, Sanders B, Bloom JJ, et al. Prevalence and Patterns of Prescription Drug Misuse among Young Ketamine Injectors. J Drug Issues 2007;37:717-36.

15. United States Census Bureau. US census data. 2010. Available from: http:/2010.census.gov/2010census/data/

16. Drug Enforcement Agency. National Forensic Laboratory Information System 2010 Midyear Report. 2010, Office of Diversion Control, Department of Justice. Available from: http://www.deadiversion.usdoj.gov/nflis/2010midyear.pdf

17. National Drug Intelligence Center. National Drug Threat Assessment 2009. 2008 Dec. NDIC publication; document ID: 2008Q0317-005. Available from: http://www.justice.gov/ndic/pubs31/ 31379/heroin.htm

18. Hernandez SH, Nelson LS. Prescription drug abuse: insight into the epidemic. Clin Pharmacol Ther 2010;88:307-17.

19. Watters J, Biernacki P. Targeted sampling: Options for the study of hidden populations. Soc Problems 1989;36:416-30.

20. Biernacki P, Waldorf D. Snowball sampling: Problems and techniques of chain referral sampling. Soc Meth Res 1981;10:141-63.

21. Benjamini Y, Hochberg Y. Controlling the false discovery rate: a practical and powerful approach to multiple testing. J R Statist Soc Series B 1995;57:289-300.

22. Brown BW, Russell K. Methods correcting for multiple testing: operating characteristics. Statist Med 1997;16:2511-28.

23. Miller RL. The Encyclopedia of Addictive Drugs. 2002, Greenwood Press, Westport, CT, USA.

24. Ciccarone D, Unick GJ, Kraus A. Impact of South American heroin on the US heroin market 1993-2004. Int J Drug Policy 2009;20:392401.

25. Andrade X, Sifaneck SJ, Neaigus A. Dope sniffers In New York City: An ethnography of heroin markets and patterns of use. J Drug Issues 1999;29:271-98.

26. National Drug Intelligence Center. California Central District Drug Threat Assessment. 2001 May. NDIC publication; document ID: 2001-S0387CCA-001. Available from: http://www.justice.gov/ndic/ pubs0/668/heroin.htm

27. Firestone M, Fischer B. A qualitative exploration of prescription opioid injection among street-based drug users in Toronto: behaviors, preferences and drug availability. Harm Reduct J 2008;5:3040.

28. Roy E, Arruda N, Bourgois P. The growing popularity of prescription opioid injection in downtown Montreal: New challenges for harm reduction. Subst Use Misuse 2011;46:1142-50.

29. Davis WR, Johnson BD. Prescription opioid use, misuse, and diversion among street drug users in New York City. Drug Alcohol Depend 2008;92:267-76.

30. Babor TF, Caulkins JP, Edwards G, et al. Drug Policy and the Public Good. 2010, Oxford University Press, New York, NY, USA.

31. Kerr T, Fairbairn N, Tyndall M, Marsh D, Li K, Montaner J, et al. Predictors of non-fatal overdose among a cohort of polysubstanceusing injection drug users. Drug Alcohol Depend 2007;87:39-45.

32. Wunsch MJ, Nakamoto K, Behonick G, Massello W. Opioid deaths in rural Virginia: a description of the high prevalence of accidental fatalities involving prescribed medications. Am J Addict 2009;18:514.

33. Fortuna RJ, Robbins BW, Caiola E, et al. Prescribing of controlled medications to adolescents and young adults in the United States. Pediatrics 2010;126:1108-16.

34. Faraone SV, Wilens TE. Effect of stimulant medications for attention-deficit/hyperactivity disorder on later substance use and the potential for stimulant misuse, abuse, and diversion. J Clin Psychiatry 2007;68:e28.

35. Volkow ND, McLellan TA, Cotto JH, et al. Characteristics of opioid prescriptions in 2009. JAMA 2011;305 1299-301.

36. Weissman DE, Haddox JD. Opioid pseudoaddiction-an iatrogenic syndrome. Pain 1989;36:363-6.

37. Daniulaityte RD, Carlson RG, Kenne D. Initiation to pharmaceutical opioids and patterns of misuse: Preliminary qualitative findings obtained by the Ohio Substance Abuse Monitoring Network. J Drug Issues 2006;36:787-808.

38. Grau LE, Dasgupta N, Harvey AP, et al. Illicit use of opioids: Is OxyContin a "gateway drug"? Am J Addict 2007;16:166-73. 